\title{
Predictive value of admission D-dimer for contrast-induced acute kidney injury and poor outcomes after primary percutaneous coronary intervention
}

Kai-Yang Lin ${ }^{1 \dagger}$, Han-Chuan Chen ${ }^{1 \dagger}$, Hui Jiang ${ }^{1 \dagger}$, Sun-Ying Wang ${ }^{1}$, Hong-Mei Chen ${ }^{2}$, Zhi-Yong Wu ${ }^{1}$, Feng Jiang ${ }^{1}$, Yan-Song Guo ${ }^{1 *}$ and Peng-Li Zhu ${ }^{1 *}$

\begin{abstract}
Background: DD was found to be associated with acute myocardial infarction (AMI) and renal insufficiency. However, it is uncertain whether DD is an independent risk factor of $\mathrm{Cl}-\mathrm{AKI}$ in patients undergoing $\mathrm{pPCl}$.

Methods: We prospectively enrolled 550 consecutive patients with STEMI undergoing pPCI between January 2012 and December 2016. The predictive value of admission DD for Cl-AKI was assessed by receiver operating characteristic (ROC) and multivariable logistic regression analysis. Cl-AKI was defined as an absolute serum creatinine increase $\geq 0.3 \mathrm{mg} / \mathrm{dl}$ or a relative increase in serum creatinine $\geq 50 \%$ within $48 \mathrm{~h}$ of contrast medium exposure.

Results: Overall, the incidence of CI-AKI was $13.1 \%$. The ROC analysis showed that the cutoff point of DD was 0.69 $\mu \mathrm{g} / \mathrm{ml}$ for predicting $\mathrm{Cl}$-AKI with a sensitivity of $77.8 \%$ and a specificity of $57.3 \%$. The predictive value of DD was similar to the Mehran score for CI-AKI (AUCDD $=0.729$ vs $\left.A \cup C_{\text {Mehran }}=0.722 ; p=0.8298\right)$. Multivariate logistic regression analysis indicated that DD $>0.69 \mu \mathrm{g} / \mathrm{ml}$ was an independent predictor of $\mathrm{Cl}$-AKI (odds ratio $[\mathrm{OR}]=3.37$, 95\% Cl:1.80-6.33, $p<0.0001)$. Furthermore, DD $>0.69 \mu \mathrm{g} / \mathrm{ml}$ was associated with an increased risk of long-term mortality during a mean follow-up period of 16 months (hazard ratio $=3.41,95 \% \mathrm{Cl}: 1.4-8.03, p=0.005$ ).
\end{abstract}

Conclusion: Admission DD $>0.69 \mathrm{\mu g} / \mathrm{ml}$ was a significant and independent predictor of $\mathrm{Cl}$-AKI and long-term mortality in patients undergoing $\mathrm{pPCl}$.

Keywords: D-dimer, Contrast-induced acute kidney injury, Outcome, Primary percutaneous coronary intervention

\footnotetext{
*Correspondence: ysguo1234@126.com; zpl7755@sina.com

${ }^{\dagger}$ Kai-Yang Lin, Han-Chuan Chen and Hui Jiang contributed equally to this work.

'Department of Cardiology, Shengli Clinical Medical College of Fujian Medical University, Fujian Provincial Hospital, Fujian Provincial Center for Geriatrics, Fuzhou 350001, China

Full list of author information is available at the end of the article
}

(C) The Author(s). 2020 Open Access This article is licensed under a Creative Commons Attribution 4.0 International License, which permits use, sharing, adaptation, distribution and reproduction in any medium or format, as long as you give appropriate credit to the original author(s) and the source, provide a link to the Creative Commons licence, and indicate if changes were made. The images or other third party material in this article are included in the article's Creative Commons licence, unless indicated otherwise in a credit line to the material. If material is not included in the article's Creative Commons licence and your intended use is not permitted by statutory regulation or exceeds the permitted use, you will need to obtain permission directly from the copyright holder. To view a copy of this licence, visit http://creativecommons.org/licenses/by/4.0/ The Creative Commons Public Domain Dedication waiver (http://creativecommons.org/publicdomain/zero/1.0/) applies to the data made available in this article, unless otherwise stated in a credit line to the data. 


\section{Background}

Contrast-induced acute kidney injury (CI-AKI) is a common complication following coronary intervention procedures, which was associated with poor outcomes including dialysis, mortality, longer hospitalization and increased health-care costs [1-3], especially among patients undergoing primary percutaneous coronary intervention (pPCI) $[4,5]$. Therefore, it is important to identify the patients who are likely to develop CI-AKI and take early preventive measures in this population.

$\mathrm{D}$-dimer (DD) is a degradation product of cross-linked fibrin and a thrombosis marker, which is a wellestablished test and often used in the diagnosis and exclusion of pulmonary embolism and venous thromboembolism [6]. Ruptured plaque-induced thrombosis is a major cause of acute coronary syndrome (ACS) [7]. In recent years, DD has been reported to be a marker for the early diagnosis of ACS presenting with chest pain [8] and acute myocardial infarction (AMI) [9] . Furthermore, DD has been found to be associated with short-, mid- and long-term poor outcomes in patient with AMI [10-12]. In addition, as a marker of increased coagulability and fibrinolysis, DD also has been documented to be associated with renal insufficiency, which indicated that DD concentration increased significantly with increasing creatinine levels [13] or decreasing estimated glomerular filtration rate (GFR) [14]. However, none of the existing studies have established the relationship between DD levels and CI-AKI in patients after pPCI. Therefore, in a prospective single-center registry of patients undergoing pPCI, we sought to determine the predictive value of elevated admission DD levels for CI-AKI in patients with ST-elevation myocardial infarction (STEMI).

\section{Methods}

\section{Study population}

This is a prospective observational study conducted at $\mathrm{Fu}-$ jian Provincial Hospital, Fujian Cardiovascular Institute, from January 2012 to December 2016. A total of 639 consecutive patients with STEMI undergoing primary percutaneous coronary intervention (pPCI) were enrolled. Exclusion criteria were pregnancy, lactation, malignant tumor and $<1$ year of life expectancy,end-stage renal disease (eGFR $<15 \mathrm{~mL} / \mathrm{min} / 1.73 \mathrm{~m}^{2}$ ), long-term dialysis treatment, intra-vascular administration of contrast medium within the last 7 or 3 days postoperatively, lack of postprocedural serum creatinine $(\mathrm{SCr})$ within $48 \mathrm{~h}$ after $\mathrm{PCI}$, drug taking that decreasing kidney function $48 \mathrm{~h}$ before CM exposure,including sodium bicarbonate, non-steroidal anti-inflammatory drugs (NSAIDs), metformin, aminoglycoside drugs, cyclosporine, cisplatin and so on and severe valvular heart disease or preparation for other operations. Finally, 550 patients were included in the analysis. The study was approved by an institutional review committee and the subjects gave informed consent.

\section{Laboratory investigations, cardiac catheterization and medications}

The serum concentration of DD was measured at admission for each patient before PCI. SCr was measured at admission and daily for the 2 days after contrast exposure. We also measured blood urea nitrogen (BUN), international normalized ratio (INR), fibrinogen, troponin I, Nterminal pro-B-type natriuretic peptide (NT-proBNP), white blood cell count, platelet, hemoglobin, and other parameters before PCI. PCI was performed by experienced interventional cardiologists according to standard clinical practice using standard guide catheters, guide wires, balloon catheters and stents via the femoral or radial approach. All patients received nonionic, low-osmolar contrast media (either Iopamiron or Ultravist, both $370 \mathrm{mg} \mathrm{I} /$ $\mathrm{mL}$ ). In addition, $0.9 \%$ normal saline at a rate of $1 \mathrm{~mL} / \mathrm{kg} /$ $\mathrm{h}$ was administered intravenously approximately $12 \mathrm{~h}$ during perioperative period $(0.5 \mathrm{~mL} / \mathrm{kg} / \mathrm{h}$ if patients with heart failure). The use of medications includs antiplatelet agents (aspirin/clopidogrel), $\beta$-adrenergic blocking agents, statins, angiotensin-converting enzyme inhibitor (ACEI)/ angiotensin receptor blocker (ARB), and other drugs which were at the discretion of the cardiologists according to clinical protocols based on interventional guidelines.

\section{Definitions and follow-up}

The primary end point was CI-AKI, defined as an absolute $\mathrm{SCr}$ increase $\geq 0.3 \mathrm{mg} / \mathrm{dl}$ or a relative increase in serum creatinine $\geq 50 \%$ within $48 \mathrm{~h}$ of contrast medium exposure [15]. Additional end points included inhospital outcomes [i.e.motality, recurrent myocardial infarction (MI), required renal replacement therapy (RRT), stent thrombosis, bleeding and length of hospital stay, hospital costs, and mortality] and long-term major adverse clinical events (MACEs). MACEs included mortality, stent restenosis, non-fatal myocardial infarction and target vessel revascularization (TVR).

The eGFR was calculated using the modified modification of diet in renal disease equation: $186.3 \times \mathrm{SCr}^{-1.154} \times$ (age in years) ${ }^{-0.203} \times 1.212$ (if patient was black) $\times 0.742$ (if patient was female) [16].

Peri-hypotension was defined as systolic blood pressure $(\mathrm{SBP})<80 \mathrm{mmHg}$ for at least $1 \mathrm{~h}$ requiring inotropic support with medications or intra-aortic balloon pump (IABP) within $24 \mathrm{~h}$ peri-procedure [17].

All patients were subject to follow-up for more than one year. Follow-up events were carefully monitored and recorded by trained nurses using either outpatient clinical visits or telephone contact with the patients or their relatives after discharge. 


\section{Statistical analysis}

All data were analyzed with SPSS version 20.0. We compared the baseline characteristics among 4 groups divided by DD quartiles. Normally distributed continuous variables are expressed as mean + standard deviation (SD). The Student's t-test, Wilcoxon rank sum test or one way-analysis of variance was performed to determine the differences among groups. Categorical variables were compared by chi-square test or Fisher exact test. The receiver operating characteristic (ROC) curve was conducted to determine the cutoff value of DD and the Mehran score for CI-AKI.The difference between DD and the Mehran score for predicting CI-AKI was performed by nonparametric tests. Multivariate logistic regression analyses were performed to identify independent risk factors of CI-AKI. Cox regression analysis were performed to identify independent risk factors of long-term poor outcomes and the Kaplan-Meier curve was used to assess the survival time between different groups with log-rank test. A 2 -sided $p$ value $<.05$ was considered significant.

\section{Results}

\section{Baseline characteristics}

This study included 550 consecutive patients, of whom 72 (13.1\%) developed CI-AKI.The mean age was $63.50+$ 12.15 years and 67 (12.2\%) were female. Baseline characteristics are described in Table 1, the patients were stratified into four DD quartiles: $<0.38 \mu \mathrm{g} / \mathrm{ml}, 0.38-0.67 \mu \mathrm{g} / \mathrm{ml}, 0.68-$ $1.03 \mu \mathrm{g} / \mathrm{ml}$, and $>1.03 \mu \mathrm{g} / \mathrm{ml}$. Patients in the higher DD group were significantly older, more likely to have anemia and worse renal function, had higher baseline of NTproBNP, cholesterol, low density lipoprotein-cholesterol (LDL-C), fibrinogen, INR, Mehran score, and had a higher percentage of perioperative hypotension, use of contrast volume and IABP, but lower diastolic blood pressure and left ventricular ejection fraction (LVEF). And baseline vascular acess between CI-AKI group and Non-CIAKI group are described in Supplement Table 1.

\section{DD level predicts $\mathrm{Cl}-\mathrm{AKI}$ by ROC curve}

A DD cutoff point of $0.69 \mu \mathrm{g} / \mathrm{ml}$ predicted by the ROC curve had a sensitivity of $77.8 \%$ and a specificity of $57.3 \%$ (AUC $=0.729,95 \%$ confidence interval [CI]: 0.690$0.766, p<0.0001$; Fig. 1). The predictive value of DD was similar to the Mehran score for CI-AKI $\left(\mathrm{AUC}_{\mathrm{DD}}=0.729\right.$ vs $\left.\mathrm{AUC}_{\text {Mehran }}=0.722, p=0.8298\right)$. (Fig. 1).

\section{In-hospital, 6-months and 1-year adverse events}

The incidences of CI-AKI, in-hospital mortality and required RRT were significantly higher in patients with $\mathrm{DD}>0.69 \mu \mathrm{g} / \mathrm{ml}$ than $\mathrm{DD} \leq 0.69 \mu \mathrm{g} / \mathrm{ml}(23.0 \%$ vs $5.2 \%$, $7.4 \%$ vs $1.0,2.9 \%$ vs $0.3 \%$, all $p<0.05)$. Patients with $\mathrm{DD}>0.69 \mu \mathrm{g} / \mathrm{m}$ also had significantly higher 6-month and 12 -month mortality $(9.0 \%$ vs $1.0,9.8 \%$ vs $1.6 \%$, both $p<.05)$ and much higher hospital costs $(76,070.04 \pm 43$, 063.55 vs $66,165.01 \pm 28,815.73$ renminbi; $p<.01)$.

Furthermore, CI-AKI was related to higher risk of inhospital mortality $(16.7 \%$ vs $1.9 \%, p<.001)$, required RRT, bleeding( $16.7 \%$ vs $1.9,5.6 \%$ vs $0.8,5.6 \%$ vs $0.8 \%$, all $p<.05)$, and significantly increased hospital stay length and hospital costss $(15.21 \pm 10.30$ vs $12.75 \pm 6.42,88,876.34 \pm 56$, 971.9 vs $67,989.403 \pm 1357.43$ renminbi; $p<.01$ ). (Table 2 ).

\section{Risk factors of $\mathrm{Cl}-\mathrm{AKI}$}

Univariate logistic regression analysis indicated that the contrast volume $\geq 200 \mathrm{ml}$, LVEF $<.45$, $\mathrm{SCr}$, perioperative hypotension, use of IABP, and DD $>0.69 \mu \mathrm{g} / \mathrm{ml}$ were significantly associated with CI-AKI after pPCI (all $p<.05)$. After adjusting for potential confounding risk factors, LVEF < .45(adjusted odds ratio [OR] 2.79, 95\% CI 1.47$5.28, p=.002)$, SCr (OR 2.84, 95\% CI 1.29-6.28, $p=.010$ ), perioperative hypotension (OR $2.03,95 \% \mathrm{CI}$ $1.13-3.64, p=.017$ ), use of IABP (OR $4.55,95 \%$ CI 1.27 $16.34, p=.020)$ and $\mathrm{DD}>0.69 \mu \mathrm{g} / \mathrm{ml}(\mathrm{OR} 3.37,95 \% \mathrm{CI}$ $1.80-6.33, p<.0001)$ remained significant predictors of CI-AKI. (Fig. 2).

\section{DD level and long-term outcomes}

The median follow-up period was 16 months. Cox regression analysis revealed that DD $>0.69 \mu \mathrm{g} / \mathrm{ml}$ was an independent risk factor for long-term mortality (hazard ratio $[\mathrm{HR}]=3.41,95 \% \mathrm{CI}: 1.4-8.03, p=.005)$ after adjusting for other risk factors including LVEF $<.45$, eGFR $<$ $60 \mathrm{~mL} / \mathrm{min} / 1.73 \mathrm{~m}^{2}$, perioperative hypotension, female, anemia. (Fig. 3).

Compared with patients with $\mathrm{DD} \leq 0.69 \mu \mathrm{g} / \mathrm{ml}$, the Kaplan-Meier curve showed that patients with DD > $0.69 \mu \mathrm{g} / \mathrm{ml}$ had higher rate of all-cause mortality and MACEs $\quad$ (Chi-Square $=22.93, \quad$ Log-Rank $p<0.0001$; Chi-Square $=24.16, \quad$ Log-Rank $p<0.0001$, respectively).(Fig. 4 A-B) Patients who developed CI-AKI had a higher rate of all-cause mortality and MACEs compared with those who without (Chi-Square $=20.12$, Log-Rank $p<0.0001$; Chi-Square $=16.24, \quad$ Log-Rank $p<0.0001$,respectively).(Fig. 5 A-B).

\section{Discussion}

To our knowledge, this study is the first to investigate the relationship between DD and CI-AKI. The main finding of our study was that the elevation of admission DD was markedly related to the incidence of CI-AKI. $\mathrm{DD}>0.69 \mu \mathrm{g} / \mathrm{L}$ was found to be the best cutoff point for predicting CI-AKI with a sensitivity of $77.8 \%$ and a specificity of $57.3 \%$ after pPCI, which exhibited similar predict value to the Mehran score. Furthermore, DD >0.69 $\mu \mathrm{g} / \mathrm{L}$ was also strongly associated with in-hospital and long-term mortality in this population. 
Table 1 Baseline Characteristics Among the 4 Groups Divided by DD Quartiles

\begin{tabular}{|c|c|c|c|c|c|}
\hline Variables & $\begin{array}{l}\text { Q1 } \\
(n=141) \\
(<0.38)\end{array}$ & $\begin{array}{l}\text { Q2 } \\
(n=140) \\
(0.38-0.67)\end{array}$ & $\begin{array}{l}\text { Q3 } \\
(n=135) \\
(0.68-1.03)\end{array}$ & $\begin{array}{l}\text { Q4 } \\
(n=134) \\
(>1.03)\end{array}$ & $p$ \\
\hline \multicolumn{6}{|l|}{ Demographics } \\
\hline Age, years & $59.79 \pm 11.54$ & $61.48 \pm 12.46$ & $64.51 \pm 11.17$ & $68.48 \pm 11.68$ & $<0.0001$ \\
\hline Age > 75 years, $n(\%)$ & $9(6.4 \%)$ & $16(11.4 \%)$ & $25(18.5 \%)$ & $45(33.6 \%)$ & $<0.0001$ \\
\hline Sex, female, n (\%) & $10(7.1 \%)$ & $14(10.0 \%)$ & $22(16.3 \%)$ & $21(15.7 \%)$ & 0.053 \\
\hline Systolic blood pressure, $\mathrm{mmHg}$ & $122.39 \pm 23.44$ & $123.73 \pm 22.25$ & $121.80 \pm 22.66$ & $116.52 \pm 23.86$ & 0.123 \\
\hline Diastolic blood pressure,mmHg & $74.84 \pm 17.49$ & $75.10 \pm 15.98$ & $72.89 \pm 16.38$ & $68.37 \pm 15.56$ & 0.012 \\
\hline Heart rate,bpm & $77.06 \pm 12.07$ & $79.16 \pm 14.85$ & $77.92 \pm 15.47$ & $77.98 \pm 16.23$ & 0.795 \\
\hline \multicolumn{6}{|l|}{ Medical history } \\
\hline Previous PCl, n (\%) & $3(2.1 \%)$ & $5(3.6 \%)$ & $5(3.7 \%)$ & $5(3.7 \%)$ & 0.851 \\
\hline Smoker, n (\%) & $85(60.3 \%)$ & $86(61.4 \%)$ & $76(56.3 \%)$ & 79 (59.0\%) & 0.842 \\
\hline Diabetes, n (\%) & $35(24.8 \%)$ & $30(21.4 \%)$ & $35(25.9 \%)$ & $40(29.9 \%)$ & 0.456 \\
\hline Hypertension, n (\%) & $78(55.3 \%)$ & $81(57.9 \%)$ & $79(58.5 \%)$ & $82(61.2 \%)$ & 0.804 \\
\hline Anemia, n (\%) & $26(18.4 \%)$ & $36(25.7 \%)$ & $33(24.4 \%)$ & $55(41.0 \%)$ & $<0.0001$ \\
\hline Prior Ml, n(\%) & $3(2.1 \%)$ & $3(2.1 \%)$ & $4(3.0 \%)$ & $1(0.7 \%)$ & 0.628 \\
\hline \multicolumn{6}{|l|}{ Laboratory measurements } \\
\hline Serum creatinine, mg/dl & $0.82 \pm 0.18$ & $0.82 \pm 0.19$ & $0.86 \pm 0.30$ & $1.00 \pm 0.41$ & $<0.0001$ \\
\hline Serum creatinine $>1.5 \mathrm{mg} / \mathrm{dl}, \mathrm{n}$ & $0(0.0 \%)$ & $0(0.0 \%)$ & $6(4.4 \%)$ & $13(9.7 \%)$ & $<0.0001$ \\
\hline $\mathrm{eGFR}<60 \mathrm{~mL} / \mathrm{min} / 1.73 \mathrm{~m}^{2}, \mathrm{n}(\%)$ & $3(2.1 \%)$ & $3(2.1 \%)$ & $13(9.6 \%)$ & $23(17.2 \%)$ & $<0.0001$ \\
\hline Hemoglobin, g/L & $143.04 \pm 13.28$ & $141.66 \pm 15.08$ & $140.81 \pm 14.76$ & $136.04 \pm 19.99$ & 0.002 \\
\hline Hematocrit & $0.41 \pm 0.04$ & $0.41 \pm 0.04$ & $0.41 \pm 0.04$ & $0.40 \pm 0.06$ & 0.008 \\
\hline Cholesterol, $\mathrm{mmol} / \mathrm{L}$ & $5.00 \pm 1.08$ & $4.95 \pm 1.24$ & $4.75 \pm 1.09$ & $4.58 \pm 1.10$ & 0.007 \\
\hline $\mathrm{LDL}-\mathrm{C}, \mathrm{mmol} / \mathrm{L}$ & $3.40 \pm 0.99$ & $3.39 \pm 1.06$ & $3.21 \pm 0.98$ & $3.02 \pm 1.00$ & 0.007 \\
\hline Triglycerides, mmol/L & $1.70 \pm 1.25$ & $1.48 \pm 1.01$ & $1.39 \pm 0.93$ & $1.44 \pm 1.33$ & 0.103 \\
\hline LgNT-pro-BNP, pg/mL & $2.26 \pm 0.60$ & $2.26 \pm 0.63$ & $2.40 \pm 0.59$ & $2.60 \pm 0.75$ & $<0.0001$ \\
\hline Fibrinogen, $\mathrm{g} / \mathrm{L}$ & $3.44 \pm 0.75$ & $3.51 \pm 0.97$ & $3.52 \pm 0.92$ & $3.78 \pm 1.06$ & 0.020 \\
\hline INR & $1.08 \pm 0.10$ & $1.09 \pm 0.10$ & $1.15 \pm 0.30$ & $1.16 \pm 0.14$ & $<0.0001$ \\
\hline $\mathrm{DD}, \mathrm{ug} / \mathrm{ml}$ & $0.25 \pm 0.08$ & $0.52 \pm 0.09$ & $0.85 \pm 0.10$ & $1.71 \pm 1.42$ & $<0.0001$ \\
\hline LVEF & $56.17 \pm 7.57$ & $54.08 \pm 7.31$ & $53.91 \pm 7.24$ & $49.63 \pm 9.67$ & $<0.0001$ \\
\hline LVEF $<0.45, n(\%)$ & $9(6.4 \%)$ & $17(12.1 \%)$ & $17(12.6 \%)$ & $42(31.3 \%)$ & $<0.0001$ \\
\hline \multicolumn{6}{|l|}{ Medication } \\
\hline Statin use, n (\%) & $140(99.3 \%)$ & $140(100.0 \%)$ & $135(100.0 \%)$ & $132(98.5 \%)$ & 0.285 \\
\hline Antiplatelet agents use, n (\%) & $141(100.0 \%)$ & 140 (100.0\%) & $135(100 \%)$ & $132(98.5 \%)$ & 0.101 \\
\hline \multicolumn{6}{|l|}{ Procedural characteristic } \\
\hline Perioperative IABP, n (\%) & $0(0.0 \%)$ & $2(1.4 \%)$ & $3(2.2 \%)$ & $8(6.0 \%)$ & 0.009 \\
\hline Perioperative hypotension, n (\%) & $47(33.3 \%)$ & $42(30.0 \%)$ & 49 (36.3\%) & $62(46.3 \%)$ & 0.034 \\
\hline Contrast volume, $\mathrm{ml}$ & $167.80 \pm 53.57$ & $181.79 \pm 50.74$ & $187.19 \pm 51.93$ & $189.18 \pm 53.76$ & 0.003 \\
\hline Contrast volume $\geq 150 \mathrm{ml}, \mathrm{n}(\%)$ & $79(56.0 \%)$ & $100(71.4 \%)$ & $100(74.1 \%)$ & $103(76.9 \%)$ & 0.001 \\
\hline Number of stents & $1.34 \pm 0.54$ & $1.33 \pm 0.55$ & $1.33 \pm 0.52$ & $1.18 \pm 0.42$ & 0.116 \\
\hline Number of diseased vessels, $\mathrm{n}$ & $2.16 \pm 0.90$ & $2.18 \pm 0.86$ & $2.41 \pm 0.81$ & $2.23 \pm 0.83$ & 0.147 \\
\hline Stent length,mm & $36.62 \pm 17.54$ & $35.10 \pm 17.52$ & $36.92 \pm 18.39$ & $31.75 \pm 12.17$ & 0.134 \\
\hline Merhan risk score & $7.50 \pm 4.99$ & $8.04 \pm 4.50$ & $8.97 \pm 5.48$ & $11.64 \pm 5.79$ & $<0.0001$ \\
\hline
\end{tabular}


Table 1 Baseline Characteristics Among the 4 Groups Divided by DD Quartiles (Continued)

\begin{tabular}{lllll}
\hline Variables & $\begin{array}{l}\mathrm{Q} 1 \\
(n=141) \\
(<0.38)\end{array}$ & $\begin{array}{l}\mathrm{Q} 2 \\
(n=140)\end{array}$ & $\begin{array}{l}\mathrm{Q} 3 \\
(n=135) \\
(0.38-0.67)\end{array}$ & $\begin{array}{l}\mathrm{Q} 4 \\
(n=134) \\
(>1.03)\end{array}$ \\
\hline $\begin{array}{l}\text { Vascular access } \\
\text { Radial access }\end{array}$ & $125(88.7 \%)$ & $120(85.7 \%)$ & $121(89.6 \%)$ & $117(87.3 \%)$ \\
Femoral accessra & $16(11.3 \%)$ & $17(12.2 \%)$ & $11(8.2 \%)$ & $14(10.5 \%)$ \\
$\quad$ Radial access + femoral access & $0(0.0 \%)$ & $3(2.1 \%)$ & $3(2.2 \%)$ & $3(2.2 \%)$ \\
\hline
\end{tabular}

Abbreviations: $D D$ D-Dimer; $P C l$ percutaneous coronary intervention, $M I$ myocardial infarction, $L V E F$ left ventricular ejection fraction, eGFR estimated glomerular filtration rate, $L D L-C$ low density lipoprotein-cholesterol, NT-pro-BNP N-terminal pro-B-type natriuretic peptide, INR international normalized ratio, IABP intra-aortic balloon pump

Previous studies had demonstrated that an increased risk of CI-AKI in patients undergoing pPCI compare with elective PCI [18-20], as the patients who underwent pPCI usually accompanied by hemodynamic instability, severe heart failure, and insufficient hydration. In our study, the incidence of CI-AKI in patients undergoing pPCI was up to $13.1 \%$, which was consistent with the data available in the literature $[21,22]$.

Multiple risk factors have been confirmed to be associated with CI-AKI and several risk models have been applied to predict CI-AKI in clinical practice. Merhan score is the most common tool for using in the assessment of the risk of CI-AKI. However, the score need 8 periprocedural risk factors including hypotension, intra-aortic balloon pump, congestive heart failure, chronic kidney disease, diabetes, age > 75 years, anemia, and volume of contrast, some of which are not available before pPCI [17]. In our study, we also have found LVEF $<0.45, \mathrm{SCr}$, perihypotension, use of IABP were independent risk factors for prediciting CI-AKI, as well as DD may be a new biomarker for predicting CI-AKI in patients undergoing $\mathrm{pPCI}$, which was not significantly different from the Merhan CI-AKI score $(P=0.410)$. In addition, the DD test is routinely performed at admission in our department for patients with cardivoscular disease. Therefore, compared with Mehran score, DD may be a more easily and timely available tool for identifying high-risk patients of CI-AKI in STEMI patients undergoing pPCI.

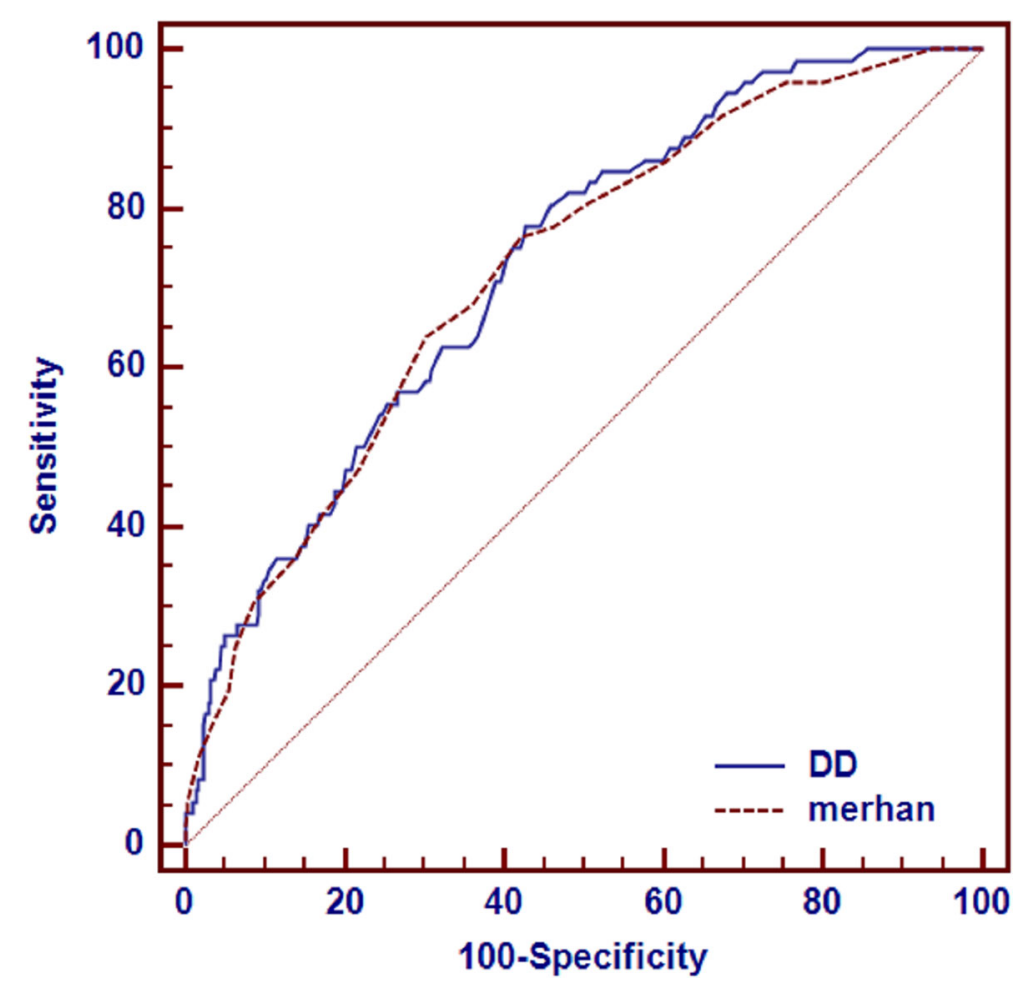

Fig. 1 ROC curves of DD and Mehran score for Cl-AKI 
Table 2 Incidence of In-Hospital Outcomes

\begin{tabular}{|c|c|c|c|c|c|c|}
\hline Outcome & $\mathrm{DD} \leq 0.69(n=306)$ & $\begin{array}{l}\mathrm{DD}>0.69 \\
(n=244)\end{array}$ & $P$-value & $\begin{array}{l}\text { CI-AKI(-) } \\
(n=478)\end{array}$ & $\begin{array}{l}\text { Cl-AKI (+) } \\
(n=72)\end{array}$ & $P$-value \\
\hline$\overline{\mathrm{Cl}-\mathrm{AKI}}$ & $16(5.2 \%)$ & $56(23.0 \%)$ & $<0.0001$ & & & \\
\hline In-hospital mortality, n (\%) & $3(1.0 \%)$ & $18(7.4 \%)$ & $<0.0001$ & $9(1.9 \%)$ & $12(16.7 \%)$ & $<0.000$ \\
\hline Recurrent MI, n (\%) & $1(0.3 \%)$ & $4(1.6 \%)$ & 0.176 & $4(0.8 \%)$ & $1(1.4 \%)$ & 0.506 \\
\hline Required RRT, n (\%) & $1(0.3 \%)$ & $7(2.9 \%)$ & 0.025 & $4(0.8 \%)$ & $4(5.6 \%)$ & 0.013 \\
\hline Stent thrombosis, n (\%) & $1(0.3 \%)$ & $1(0.4 \%)$ & 1.000 & $1(0.2 \%)$ & $1(1.4 \%)$ & 0.245 \\
\hline Bleeding, n (\%) & $4(1.3 \%)$ & $4(1.6 \%)$ & 0.738 & $4(0.8 \%)$ & $4(5.6 \%)$ & 0.013 \\
\hline Hospitalization length, days & $12.52 \pm 6.49$ & $13.72 \pm 7.68$ & 0.081 & $12.75 \pm 6.42$ & $15.21 \pm 10.30$ & 0.015 \\
\hline Hospital costs, RMB & $66,165.01 \pm 28,815.73$ & $76,070.04 \pm 43,063.55$ & 0.005 & $67,989.403 \pm 1357.43$ & $88,876.34 \pm 56,971.9$ & $<0.000$ \\
\hline 6-months mortality & $3(1.0 \%)$ & $22(9.0 \%)$ & $<0.0001$ & $13(2.7 \%)$ & $12(16.7 \%)$ & $<0.000$ \\
\hline 12-months mortality & $5(1.6 \%)$ & 24 (9.8\%) & $<0.0001$ & 17 (3.6\%) & $12(16.7 \%)$ & $<0.000$ \\
\hline
\end{tabular}

Abbreviations: $C I-A K I$ contrast-induced acute kidney injury, DD D-Dimer, RRT renal replacement therapy, $M I$ mycardial infarction, $R M B$ renminbi

DD is a plasmin-derived soluble degradation product of cross-linked fibrin, which could provide a rapid assessment of thrombotic activity and the severity of thrombotic burden [23], reflecting the diagnosis and prognosis of many disorders. DD has been already widely accepted in diagnosis of venous thromboembolism and pulmonary embolism which is sensitive but not well specific [24-26]. Moreover, numerous studies found that DD testing was also valuable in other disease, especially cardiovascular disease such as acute aortic dissection [27], atrial fibrillation [28], heart failure $[29,30]$ and so on.
Previous studies also found that elevated DD level was a useful biomarker for kidney disease. Michael G. Shlipak et al. evaluated a population-based cohort study of 5888 subjects aged $\geq 65$ years from Cardiovascular Health Study, and showed that [31] DD levels were significantly higher among patients with renal insufficiency $(P=0.0002)$ and increased as renal function declined regardless of cardiovascular disease status $(p=0.004)$. The conclusion was similar to the study by Wannamethee, S. G et al., which indicated that activated coagulation marker (DD) increased with decreasing eGFR in elderly men [32]. Spring $\mathrm{JL}$ also demonstrated that [13] there was a statistically

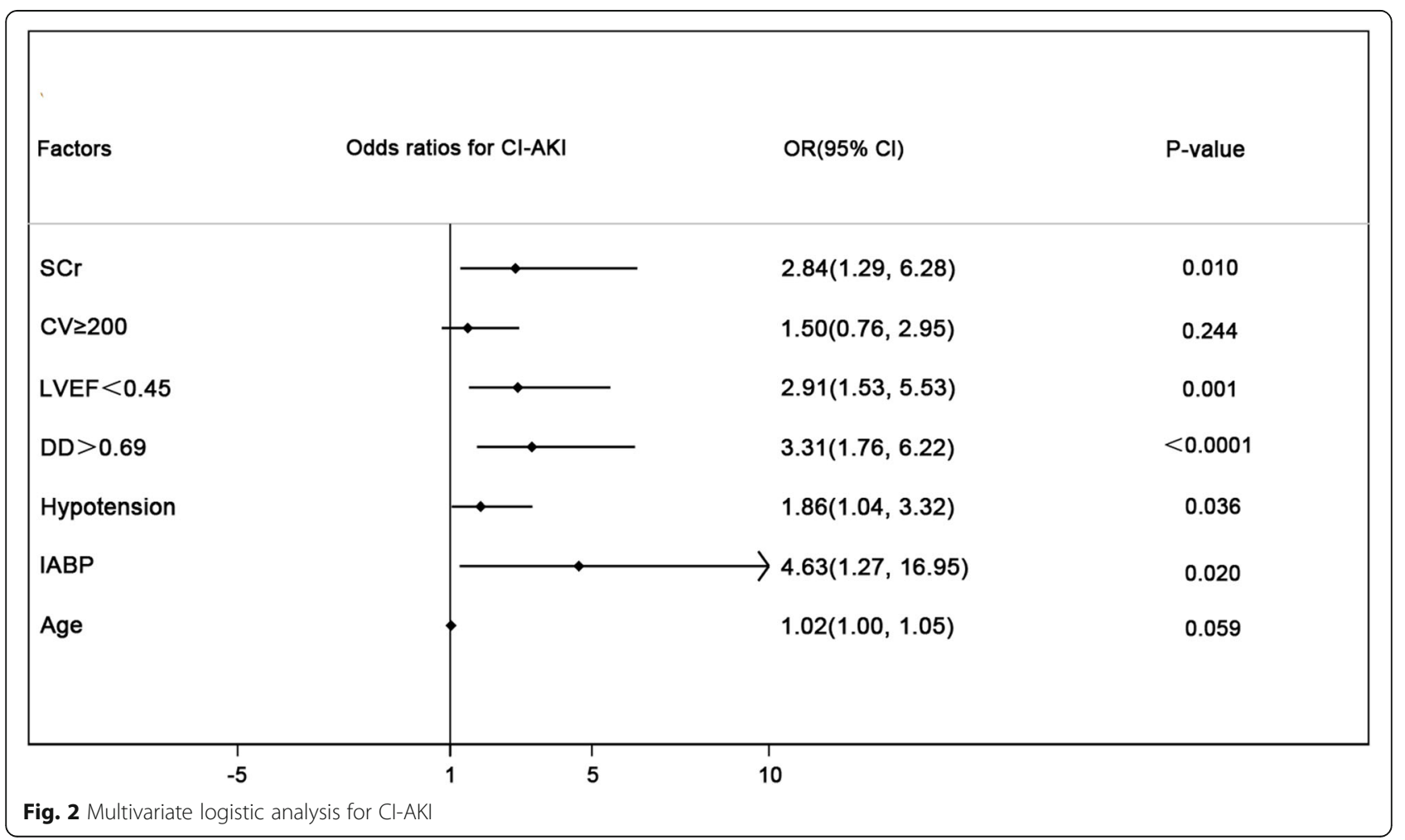




\begin{tabular}{|c|c|c|c|}
\hline Factors & Hazard ratios for Long-term Mortality & $\mathrm{HR}(95 \% \mathrm{Cl})$ & P-value \\
\hline LVEF $<0.45$ & - & $4.08(2.06,8.09)$ & $<0.0001$ \\
\hline eGFR $<60$ & - & $1.73(0.78,3.80)$ & 0.175 \\
\hline $\mathrm{DD}>0.69$ & $\longrightarrow$ & $3.14(1.33,7.41)$ & 0.009 \\
\hline Age & & $1.05(1.02,1.09)$ & 0.003 \\
\hline Hypotension & & $1.45(0.74,2.82)$ & 0.277 \\
\hline Female & & $1.42(0.65,3.08)$ & 0.376 \\
\hline Anemia & & $1.41(0.72,2.75)$ & 0.318 \\
\hline $\begin{array}{l}1 \\
-5\end{array}$ & $\begin{array}{l}1 \\
5\end{array}$ & $\begin{array}{c}1 \\
10\end{array}$ & \\
\hline
\end{tabular}

significant correlation between DD concentration and renal function in the critically ill patients. Another recent study [14] found that in patients undergoing cardiac surgery, prothrombin fragment 1.2 (coagulation marker) levels were significantly higher in the AKI group $(506 \pm 548 \mathrm{vs} .999 \pm 704.1 \mathrm{pmol} / \mathrm{L} ; p=0.018)$ and they were independently associated with eGFR reduction, with an area under the ROC of 0.744 . The association between the degree of coagulation's activation and AKI following cardiac operations may be partly explained by microcirculation impairment and dysfunction of endothelial cells. As were described above, DD were reported to be an important biomarker in patients with renal insufficiency or AKI. However, to our knowledge, there was not even a study focusing on the relationship between DD levels and CI-AKI. Now our results fill in this gap by documented that elevated DD level was a strong and independent predictor of CI-AKI after pPCI and CI-AKI, even after adjusting for potential confounding factors. Meanwhile, a pre-procedural DD levels $>0.69 \mu \mathrm{g} / \mathrm{ml}$ was found to be a best cutoff point for predicting the
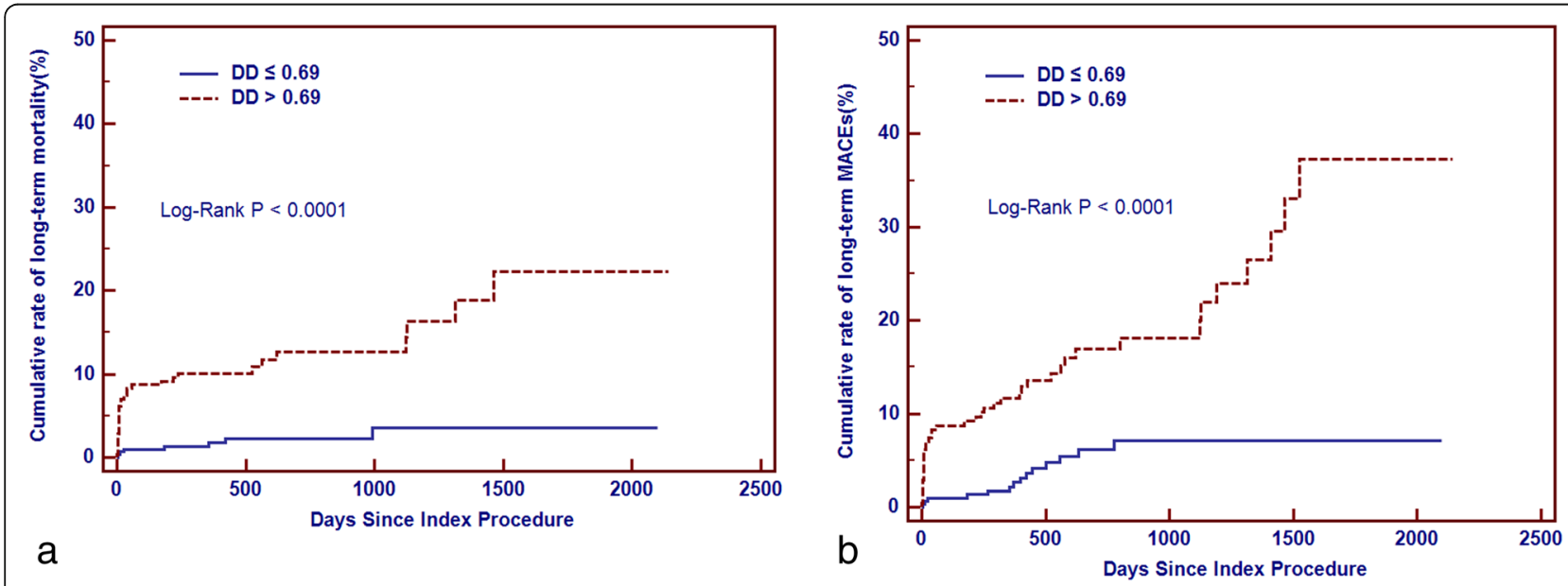

Fig. 4 a Cumulative rate of mortality between patients with low DD and high DD level. b Cumulative rate of MACEs between patients with low DD and high DD level 

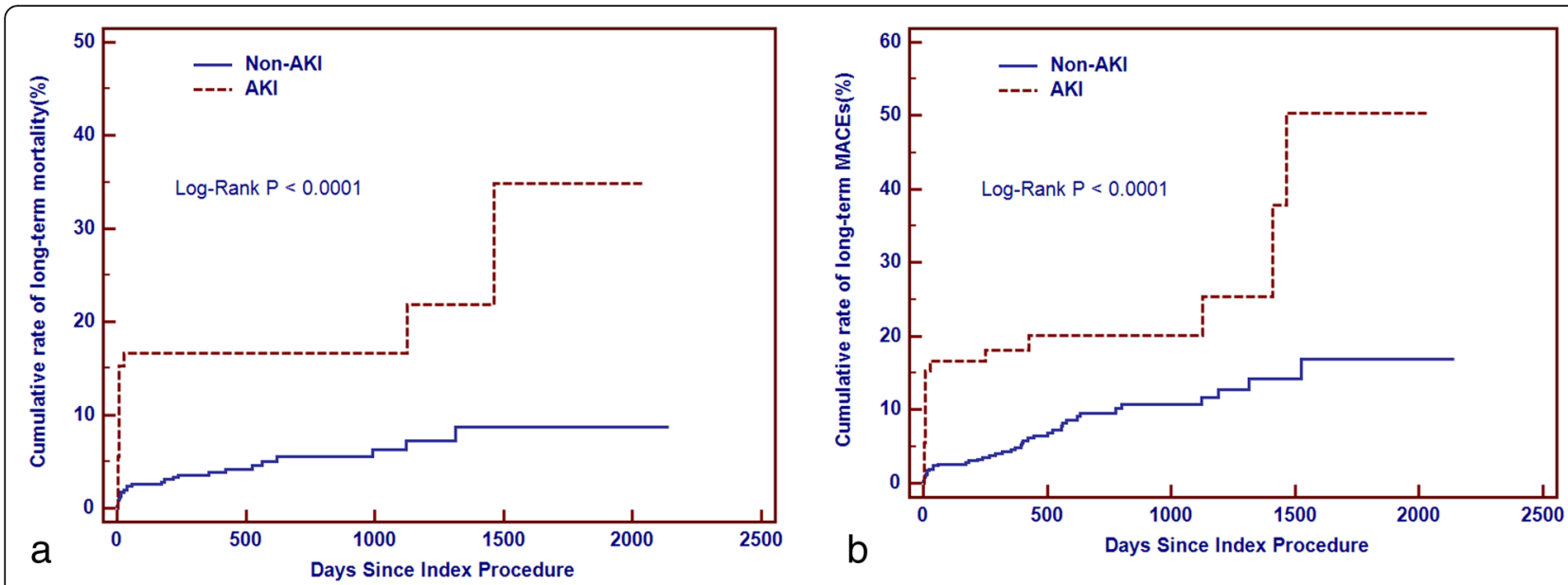

Fig. 5 a Cumulative rate of mortality between patients with AKI and non-AKI. $\mathbf{b}$ Cumulative rate of MACEs between patients with AKI and non-AKI

risk of CI-AKI, with $77.8 \%$ sensitivity and $57.3 \%$ specificity, which exhibited similar predictive value to the Mehran score.

The mechanisms underlying the association between DD levels and CI-AKI is uncertain. The potential pathophysiological mechanism may be partly explained by following. First, DD levels were confirmed to be closely related to the occurrence of no-reflow after pPCI [33] indicating that the thrombus is unstable and easily to fall off into the circulation system, which may influence the renal blood flow and further lead to CI-AKI. Second, elevated DD levels is mainly cleared through renal excretion, so higher DD levels often reflect the injury of renal function, which indirectly revealing the decline in the kidney's ability to excrete the contrast agent, further to enhance the direct cytotoxicity of contrast agent. Third, DD levels also related to other well-known risk factors for CI-AKI, such as advanced age [34], heart failure [29, 30]. However, after adjusting above potential influence factors on DD, elevated admission DD levels remained a powerful risk factor of CI-AKI, which indicated that additional pathophysiological processes might play a role on DD in STEMI patients after pPCI DD. Finally, some studies $[35,36]$ found that prothrombotic states may active inflammatory reaction through inducing the release of IL-1 $\beta$, IL6, P-selectin and so on,which may also be involved in the process of CI-AKI.

In addition, DD also was found to be potentially useful in diagnosis and prognosis in patients with AMI. Elevated serum levels of DD were first time discovered in acute transmural myocardial infarction patients after thrombolytic therapy with intravenous streptokmase in 1986 [37]. Thereafter, several evidence revealed that the diagnostic and prognostic value of elevated DD in patients with AMI. A small, single-center study of 257 patients with acute chest pain by Bayes-Genis A et al. [8] found that DD level $>500$ microg/L had an independent early diagnostic value for MI and increased the diagnostic sensitivity of the electrocardiogram and history from 73 to $92 \%$. Furthermore, DD was found to be associated with poor outcomes in patients with AMI. Akgul $\mathrm{O}$ et al. [10] demonstrated that a high admission DD level $(>0.72 \mu \mathrm{g} / \mathrm{ml}$ FEU) was a powerful independent predictor of 6-month all-cause mortality. Another study of HORIZONS-AMI trial [12] showed admission DD levels were a strong predictor of MACE in patients treated with pPCI within 3 years follow up. Compared with patients with lower DD levels $(<0.71 \mu \mathrm{g} / \mathrm{ml})$, patients with higher DD levels $(\geq 0.71 \mu \mathrm{g} / \mathrm{ml})$ on admission were associated with an adjusted hazard ratio of 2.58 for MACE. In our study, poor prognosis for short- and long-term mortality in patients undergoing $\mathrm{PPCI}$ having higher DD levels were also observed. Compared with patients with lower DD levels $(\leq 0.69 \mu \mathrm{g} / \mathrm{ml})$, patients with higher DD levels $(>0.69 \mu \mathrm{g} / \mathrm{ml})$ had significantly higher incidences of in-hospital outcomes such as CIAKI, mortality and required RRT, and increased hospital costs, as well as higher 6-month and 12-month mortality. Furthermore, DD levels $>0.69 \mu \mathrm{g} / \mathrm{ml}$ was also associated with an increased risk of all-cause mortality during 2 years of follow-up.

\section{Limitations}

We acknowledge several limitations in our study. First, this study was a single-center, observational study and may be affected by confounding and selection biases. However, we were careful to include consecutive patients. Second, data about peri-procedural hydration volume which may influence the incidence of CI-AKI was not recorded. Third, variations in the time to measurement may have led to missed peak levels of creatinine after the procedure,further to cause an underestimation 
of the true incidence of CI-AKI. Fourth, we did not analyze the relationship between DD level and the highsensitivity C-reactive protein,other proinflammatory cytokines and the incidence of no-reflow in detail,the defined mechanism of DD-induced CI-AKI is still unclear, which should be evaluated in a future trial. Fifth, we just found an indicator may be related to the occurrence of CI-AKI, whose relationship is causal or accidental remains unclear. Sixth,the consensus definition of CI-AKI may be a potential confounder when considering the specific forms of AKI which may occur in variable timeframes. Although we tried to exclude other risk factors for renal failure,it is difficult to rule out the patients developing renal failure following contrast media exposure but not having contrast nephropathy completely. Seventh, the long term kidney function was limited in our study. Despite these limitations, our results provided useful insights into the correlation of serum DD levels with the incidence of CI-AKI.

\section{Conclusions}

Our study found that admission elevated DD level may be markedly related to an increased risk of CI-AKI in patients undergoing pPCI. In addition, elevated DD level is also found to be associated with short- and long-term poor outcomes. DD is a simple, rapid, cheap laboratory test that can be performed before $\mathrm{pPCI}$ to identity the risk of CI-AKI in patients with STEMI. Patients at high risk of CI-AKI with admission elevated DD level should be paid attention to take preventive measures during the perioperative period.

\section{Supplementary information}

Supplementary information accompanies this paper at https://doi.org/10. 1186/s12882-020-01743-7.

Additional file 1: Table S1. Baseline Vascular Access between Cl-AKI

Group and Non-CIAKI Group.

\section{Abbreviations}

BUN: Blood urea nitrogen; Cl-AKl: Contrast-induced Acute Kidney Injury; DD: D-dimer; eGFR: Estimated glomerular filtration rate; IABP: Intra-aortic balloon pump; LDL-C: Low density lipoprotein-cholesterol; LVEF: Left ventricular ejection fraction; $\mathrm{pPCl}$ : Primary percutaneous coronary intervention: SCr: Serum creatinine

\section{Acknowledgements}

Not applicable.

\section{Authors' contributions}

$\mathrm{KY} \mathrm{L}, \mathrm{HC} \mathrm{C}$ and $\mathrm{H} \mathrm{J}$ contributed equally to this work and acquired the data, drafted and revised the manuscript.SY W,HM C, ZY W and F J assist to acquire and interpret the data.PL Z and YS G designed the study, provided supervision and critically revised the manuscript. All authors approve the final version of the manuscript and agree to be accountable for all aspects of the study.

\section{Funding}

This study was funded by a grant from the Joint Funds for the innovation of science and Technology, Fujian province (grant no.: 2016QH113); and Natural Science Foundation of Fujian Province (grant no:2017 J0117). The grants played a role in the design of the study, collection of data, follow-up of the patients, interpretation of data and in writing the manuscript.

\section{Availability of data and materials}

The datasets used and/or analysed during the current study are available from the corresponding author on reasonable request.

\section{Ethics approval and consent to participate}

The protocol fulfilled the requirements of the Declaration of Helsinki and was approved by the ethics committee of the Fujian Provincial Hospital, China (ethics.

approval number: K2012-001-01). An informed written consent was obtained from all the the subjects.

Consent for publication

Not applicable.

\section{Competing interests}

The authors declare that they have no competing interests.

\section{Author details}

${ }^{1}$ Department of Cardiology, Shengli Clinical Medical College of Fujian Medical University, Fujian Provincial Hospital, Fujian Provincial Center for Geriatrics, Fuzhou 350001, China. ${ }^{2}$ Department of Nursing, Fujian Provincial Hospital, Fujian Medical University, Fuzhou 350001, China.

Received: 22 September 2019 Accepted: 26 February 2020

Published online: 10 March 2020

\section{References}

1. Subramanian S, Tumlin J, Bapat B, Zyczynski T. Economic burden of contrast-induced nephropathy: implications for prevention strategies. J Med Econ. 2007:9:119-34.

2. Best PJ, Lennon R, Ting HH, Bell MR, Rihal CS, Holmes DR, et al. The impact of renal insufficiency on clinical outcomes in patients undergoing percutaneous coronary interventions. J Am Coll Cardiol. 2002;39:1113-9.

3. Rihal CS, Textor SC, Grill DE, Berger PB, Ting HH, Best PJ, et al. Incidence and prognostic importance of acute renal failure after percutaneous coronary intervention. Circulation. 2002;105:2259-64.

4. Lin KY, Shang XL, Guo YS, Zhu PL, Wu ZY, Jiang H, et al. Association of Preprocedural Hyperglycemia with Contrast-Induced Acute Kidney Injury and Poor Outcomes after Emergency Percutaneous Coronary Intervention. Angiology. 2018:69:770-8.

5. Marenzi G, Lauri G, Assanelli E, Campodonico J, De Metrio M, Marana I, et al. Contrast-induced nephropathy in patients undergoing primary angioplasty for acute myocardial infarction. J Am Coll Cardiol. 2004:44:1780-5.

6. Dunn KL, Wolf JP, Dorfman DM, Fitzpatrick P, Baker JL, Goldhaber SZ. Normal D-dimer levels in emergency department patients suspected of acute pulmonary embolism. J Am Coll Cardiol. 2002;40:1475-8.

7. Virmani R, Burke AP, Farb A, Kolodgie FD. Pathology of the vulnerable plaque. J Am Coll Cardiol. 2006:47:C13-8.

8. Bayes-Genis A, Mateo J, Santaló M, Oliver A, Guindo J, Badimon L, et al. D-dimer is an early diagnostic marker of coronary ischemia in patients with chest pain. Am Heart J. 2000;140:379-84.

9. Reihani H, Sepehri Shamloo A, Keshmiri A. Diagnostic value of D-dimer in acute myocardial infarction among patients with suspected acute coronary syndrome. Cardiol Res. 2018;9:17-21.

10. Akgul $\mathrm{O}$, Uyarel $\mathrm{H}$, Pusuroglu H, Gul M, Isiksacan N, Turen S, et al. Predictive value of elevated D-dimer in patients undergoing primary angioplasty for ST elevation myocardial infarction. Blood Coagul Fibrinolysis. 2013;24:704-10.

11. Yang J, Li CS. The predictive values of D-dimer for the early prognosis of the acute myocardial infarction (AMI): a review of $3134 \mathrm{AMI}$ patients. Zhongguo Wei Zhong Bing Ji Jiu Yi Xue. 2012;24:725-9.

12. Kikkert WJ, Claessen BE, Stone GW, Mehran R, Witzenbichler B, Brodie BR, et al. D-dimer levels predict ischemic and hemorrhagic outcomes after acute myocardial infarction: a HORIZONS-AMI biomarker substudy. J Thromb Thrombolysis. 2014;37:155-64. 
13. Spring $J$, Winkler A, Levy $J H$. The influence of various patient characteristics on D-dimer concentration in critically ill patients and its role as a prognostic indicator in the intensive care unit setting. Clin Lab Med. 2014;34:675-86.

14. Scrascia G, Rotunno C, Simone S, Montemurno E, Amorese L, De Palo M, et al. Acute kidney injury in high-risk cardiac surgery patients: roles of inflammation and coagulation. J Cardiovasc Med (Hagerstown). 2017;18: 359-65

15. Mehta RL, Kellum JA, Shah SV, Molitoris BA, Ronco C, Warnock DG, et al. Acute kidney injury network: report of an initiative to improve outcomes in acute kidney injury. Crit Care. 2007;11:R31.

16. KDOQI clinical practice guidelines for chronic kidney disease. Evaluation, classification, and stratification. Am J Kidney Dis. 2002;39:S1-266.

17. Mehran R, Aymong ED, Nikolsky E, Lasic Z, lakovou I, Fahy M, et al. A simple risk score for prediction of contrast-induced nephropathy after percutaneous coronary intervention: development and initial validation. J Am Coll Cardiol. 2004;44:1393-9.

18. Abe D, Sato A, Hoshi T, Kakefuda Y, Watabe H, Ojima E, et al. Clinical predictors of contrast-induced acute kidney injury in patients undergoing emergency versus elective percutaneous coronary intervention. Circ J. 2014; 78:85-91.

19. Bartholomew BA, Harjai KJ, Dukkipati S, Boura JA, Yerkey MW, Glazier S, et al. Impact of nephropathy after percutaneous coronary intervention and a method for risk stratification. Am J Cardiol. 2004;93:1515-9.

20. Duan C, Cao Y, Liu Y, Zhou L, Ping K, Tan MT, et al. A new Preprocedure risk score for predicting contrast-induced acute kidney injury. Can J Cardiol. 2017;33:714-23

21. Silvain J, Nguyen LS, Spagnoli V, Kerneis M, Guedeney P, Vignolles N, et al. Contrast-induced acute kidney injury and mortality in ST elevation myocardial infarction treated with primary percutaneous coronary intervention. Heart. 2018;104:767-72.

22. Centola M, Lucreziotti S, Salerno-Uriarte D, Sponzilli C, Ferrante G, Acquaviva $\mathrm{R}$, et al. A comparison between two different definitions of contrast-induced acute kidney injury in patients with ST-segment elevation myocardial infarction undergoing primary percutaneous coronary intervention. Int J Cardiol. 2016;210:4-9.

23. Weitz JI, Fredenburgh JC, Eikelboom JW. A test in context: D-dimer. J Am Coll Cardiol. 2017;70:2411-20.

24. Righini M, Van Es J, Den Exter PL, Roy PM, Verschuren F, Ghuysen A, et al. Age-adjusted D-dimer cutoff levels to rule out pulmonary embolism: the ADJUST-PE study. JAMA. 2014;311:1117-24.

25. Wells PS, Anderson DR, Rodger M, Forgie M, Kearon C, Dreyer J, et al. Evaluation of D-dimer in the diagnosis of suspected deep-vein thrombosis. N Engl J Med. 2003;349:1227-35.

26. van Belle A, Büller HR, Huisman MV, Huisman PM, Kaasjager K, Kamphuisen PW, et al. Effectiveness of managing suspected pulmonary embolism using an algorithm combining clinical probability, D-dimer testing, and computed tomography. JAMA. 2006;295:172-9.

27. Sodeck G, Domanovits $H$, Schillinger M, Ehrlich MP, Endler G, Herkner $H$, et al. D-dimer in ruling out acute aortic dissection: a systematic review and prospective cohort study. Eur Heart J. 2007;28:3067-75.

28. Hijazi Z, Oldgren J, Siegbahn A, Wallentin L. Application of biomarkers for risk stratification in patients with atrial fibrillation. Clin Chem. 2017; 63:152-64.

29. Yucel O, Yucel H, Zorlu A. D-dimer is a predictor of cardiovascular death, and new-onset atrial fibrillation in patients with systolic heart failure. Int J Cardiol. 2017;247:39

30. Hamatani $Y$, Nagai T, Nakai M, Nishimura K, Honda Y, Nakano H, et al. Elevated plasma D-dimer level is associated with short-term risk of ischemic stroke in patients with acute heart failure. Stroke. 2018;49:1737-40.

31. Shlipak MG, Fried LF, Crump C, Bleyer AJ, Manolio TA, Tracy RP, et al. Elevations of inflammatory and procoagulant biomarkers in elderly persons with renal insufficiency. Circulation. 2003;107:87-92.

32. Wannamethee SG, Shaper AG, Lowe GD, Lennon L, Rumley A, Whincup PH. Renal function and cardiovascular mortality in elderly men: the role of inflammatory, procoagulant, and endothelial biomarkers. Eur Heart J. 2006; 27:2975.

33. Erkol A, Oduncu V, Turan B, Kılıçgedik A, Sırma D, Gözübüyük G, et al. The value of plasma D-dimer level on admission in predicting no-reflow after primary percutaneous coronary intervention and long-term prognosis in patients with acute ST segment elevation myocardial infarction. J Thromb Thrombolysis. 2014;38:339-47.
34. Rumley A, Emberson JR, Wannamethee SG, Lennon L, Whincup PH, Lowe GD. Effects of older age on fibrin D-dimer, C-reactive protein, and other hemostatic and inflammatory variables in men aged 60-79 years. J Thromb Haemost. 2006;4:982-7.

35. Robson SC, Shephard EG, Kirsch RE. Fibrin degradation product D-dimer induces the synthesis and release of biologically active IL-1 beta, IL-6 and plasminogen activator inhibitors from monocytes in vitro. Br J Haematol. 1994;86:322-6.

36. Shebuski RJ, Kilgore KS. Role of inflammatory mediators in thrombogenesis. J Pharmacol Exp Ther. 2002;300:729-35.

37. Lew AS, Berberian L, Cercek B, Lee S, Shah PK, Ganz W. Elevated serum D dimer: a degradation product of cross-linked fibrin (XDP) after intravenous streptokinase during acute myocardial infarction. J Am Coll Cardiol. 1986;7: 1320-4.

\section{Publisher's Note}

Springer Nature remains neutral with regard to jurisdictional claims in published maps and institutional affiliations.
Ready to submit your research? Choose BMC and benefit from:

- fast, convenient online submission

- thorough peer review by experienced researchers in your field

- rapid publication on acceptance

- support for research data, including large and complex data types

- gold Open Access which fosters wider collaboration and increased citations

- maximum visibility for your research: over $100 \mathrm{M}$ website views per year

At BMC, research is always in progress.

Learn more biomedcentral.com/submissions 